\title{
Digital Embedding System with Heater and Cooler
}

\author{
Nur Hudha Wijaya ${ }^{1}$, Budiman Anggi Lesmana ${ }^{2}$, Nishith Shahu ${ }^{3}$, Irfan Ahmad ${ }^{4}$, Rachmad Andri Atmoko ${ }^{5}$ \\ 1,2 Department of Electrical Engineering, Universitas Muhammadiyah Yogyakarta, Yogyakarta, Indonesia \\ ${ }^{3}$ HOD Electrical Engineering, Neotech Faculty of Diploma Engineering, Gujarat Technological University, India \\ ${ }^{4}$ Departement of Electrical Engineering, Khurasan university, Nangarhat Afghanistan Afghanistan \\ ${ }^{5}$ School of Mechanical and Electrical Engineering, Guilin University of Electronic Technology, China \\ Email: hudha@umy.ac.id, budiman.anggi@vokasi.umy.ac.id, nish2687@gmail.com, irfan.ahmed.mcse@gmail.com, \\ mokoraden@hotmail.com
}

\begin{abstract}
Embedding is an anatomical pathology laboratory device that is very important for producing quality slices and is also a device used to process paraffin tissue, so that the tissue can be cut with higher precision using a microtom (slicer). From the process of melting paraffin crystals using a manual heating process with bunsen flame heaters (fire heaters) so that the paraffin crystals can be transformed from the crystal into liquid. While paraffin crystals that have been processed from the crystal to liquid form are poured into the mold and left to freeze. In this case, an embedding system device will be made equipped with heating and cooling. The temperature used for the liquefaction process is $50 \square \mathrm{C}$ while the temperature for cooling is $17 \square \mathrm{C}$. After making the process of making device, experiment device, and retrieving data, the error percentage results were $0.016 \%$ at the heating temperature and $0.08 \%$ at the coolant temperature, and the percentage of heating samples obtained in the sample was $61.3 \%$, while the percentage samples for parts coolers get a value of $92 \%$
\end{abstract}

Keywords- histopathology, embedding, temperature, microcontroller

\section{INTRODUCTION}

Histopathology is a branch of biology that studies the condition and function of tissues in relation to disease. Histopathology is very important in relation to the diagnosis of disease because one of the considerations in establishing the diagnosis is through the observation of tissue that is suspected to be disturbed. Histopathological examination is carried out through examination of abnormal changes at the tissue level. Histopathology can be done by taking tissue samples (such as in the determination of breast cancer) or by observing the tissue after death occurs. Histopathological examination aims to examine the disease based on tissue changes. This examination should be accompanied by knowledge of the normal histological picture of the tissue so that a comparison can be made between the condition of normal tissue to sample tissue (abnormal). By comparing the condition of these tissues, it can be seen whether a disease that is suspected actually attacks or not.

Histopathology technique is a method used to see changes in metabolism of tissue changes that occur. The application begins with making preparations by thinning tissue cells from the body's organs. For this reason, fine tissue can be planted in paraffin by freezing, then the tissue is cut. Requirements for obtaining an appropriate histopathology and histochemistry can be obtained by observing preparations under an electron microscope. Histopathic preparations have specific signs that are seen from cell tissue and tissue structure due to attack pathogenicity.

Embedding is an anatomical pathology laboratory device that is very important to produce quality slices and is also a device used to process paraffin tissue, so that tissue can be cut with higher precision using a microtome (slicer) [2]. Embedding nowadays is still using a manual process, which is from the process of melting paraffin crystals to the process of freezing paraffin liquids. From the process of melting paraffin crystals using a manual heating process with a bunsen flame heater that the paraffin crystals can be transformed from crystalline to liquid. While paraffin crystals that have been processed from the crystalline form into liquid are poured into a mold and then allowed to stand until they freeze. In this freezing process do not use any device, just let stand for several hours until the paraffin liquid freezes. The technology currently being developed is in the release of paraffin liquid heating, by adding a solenoid valve or an automatic faucet.

From this embedding process conducted by analysts, it usually experiences constraints of melting and freezing of paraffin. In the process of thawing and freezing the paraffin fluid is less effective. Thawing and cooling are less effective because in the process of thawing and freezing of paraffin samples that have been planted the tissue does not run perfectly, because the thawed paraffin and planted tissue is not fixed into the cooling section, it is left in the air to freeze, then the process of tissue planting does not meet the tissue planting procedure the. still using manual device and paraffin is not processed in one piece.

From the planting process a temperature control device was made. Some literature from previous researchers about temperature control is used. The design of the VehicleMounted Medical Temperature Control System was investigated by Liu [1]. The design of the Air Handling Unit Fuzzy PID Controller for Constant Temperature and Humidity of air conditioners was investigated by Shuai [2]. Autotuned PID for accurate temperature control - The heat approach was investigated by Radu [3]. Live demonstration: Wireless PID control of the thermal process using a very low cost LWIR camera was studied by Xhafa [4]. Embedded control system with PID controller for comfortable room was studied by Janprom [5]. Designing an optimal temperature control system based on the optimization of well-informed adaptive particle swarms for proton-exchange membrane fuel cells was investigated by Han [6]. Evaluation of Model-Based Controller Performance for a Data-Based Temperature 
Control System Model using an Embedded Platform was studied by Datar [7]. Reference to Adaptive Temperature Control Model of Rotary Cement Kiln was investigated by Hernandez [8]. The design and experiment of the Fuzzy PIDbased Sealing Machine Temperature Control System was investigated by Cao [9]. The application of Enhanced Smart PID Algorithm in High Precision Thermostatic Control in Trace Water Analyzer was investigated by Qiao [10].

The adaptive temperature control design of all coefficients based on the characteristic model was investigated by Jiang [11]. A humidity control system based on decoupling and the fuzzy self-tuning PID algorithm was investigated by Jingjie [12]. Digital command feedforward and PID temperature control for a PET stretch blow molding machine were investigated by Tsai [13]. The control of temperature and humidity decoupling for laboratory enthalpy differences was investigated by Li [14]. The Heuristic Control Method for Heating Systems was investigated by DU [15]. Optimized Temperature Control Self-Learning Fuzzy Algorithm and Heat Exchanger Efficiency Monitoring was investigated by Deng [16]. Application of Fuzzy Control Based on Time Series Prediction Algorithms in the Main Steam Temperature System was investigated by Zhengxin [17]. The temperature control for the Nano Particle Synthesis System was investigated by Tapia Pantoja [18]. Sanjaya [19] studied the setting of air temperature in the room for the rotational force. The control of temperature and humidity with a predictive control method in an air conditioning system was investigated by Jingyun [20].

Monitoring of Environmental Temperature of the Arduino Assistance Engineering Faculty Using Telegram was researched by Hariyanto [21]. The design method of the superheated steam thermal power switch temperature control system configuration was investigated by $\mathrm{Yu}$ [22]. The design of the Arduino-based Automatic Watering System was investigated by Prasojo [23]. The design of the TEC-based Small Temperature Control System was investigated by Huang [24]. The implementation of control algorithms for furnace temperature control in CFD simulations was studied by Bhujbal [25]. The optimal setting of the PID controller for temperature control was investigated by Doicin [26]. The temperature control solution with PLC was studied by Rata [27].

From previous research, a temperature control device was made for the paraffin planting system. This system consists of a push up / down button, LM35 temperature sensor, Arduino microcontroller, heating driver, cooling driver, and LCD. LM 35 is used in this system to measure temperature.

\section{METHOD}

\section{A. System components}

Figure 1 illustrates the block diagram of the designed device to briefly explain how the device works. From the figure, it can be seen that the system uses the LM35 sensor. The sensor is processed by the Arduino microcontroller to turn on the heating and cooling.

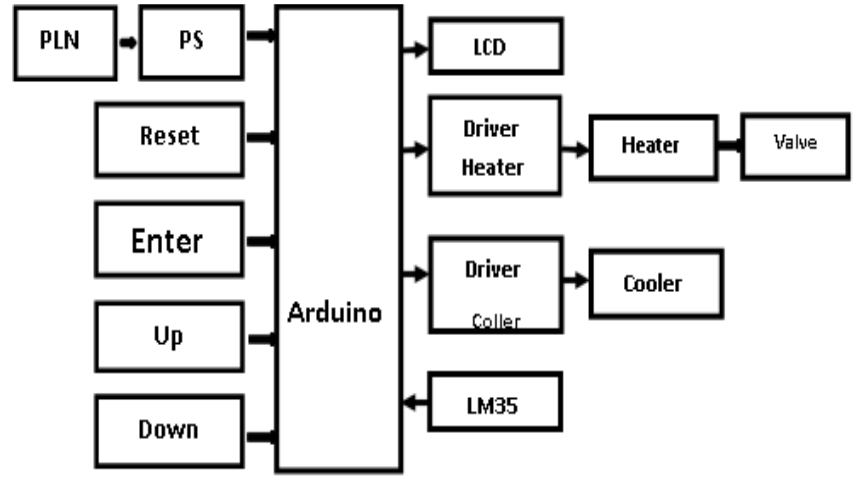

Fig. 1. System block diagram

Arduino Uno IC as the entry point for the program. At LM35 output functions to detect the temperature of the paraffin in the chamber and detect the temperature of the air inside the Cold Plate. LCD output functions to display temperature. The heater driver output serves to turn on and off the heater, the function of the heater to heat the paraffin in the chamber. While the output of the cooling driver works to turn off the cooler. The function of this cooler is to cool the paraffin liquid that has been planted with tissue slices. The reset button is used to return the device to the initial menu.

\section{B. System work flow}

Figure 2 shows the flow chart of the system. From the figure, it can be seen that the system must initialize the microcontroller registers used. Then the system makes arrangements for heating and cooling. Keys are used in the system to turn on heating and cooling.

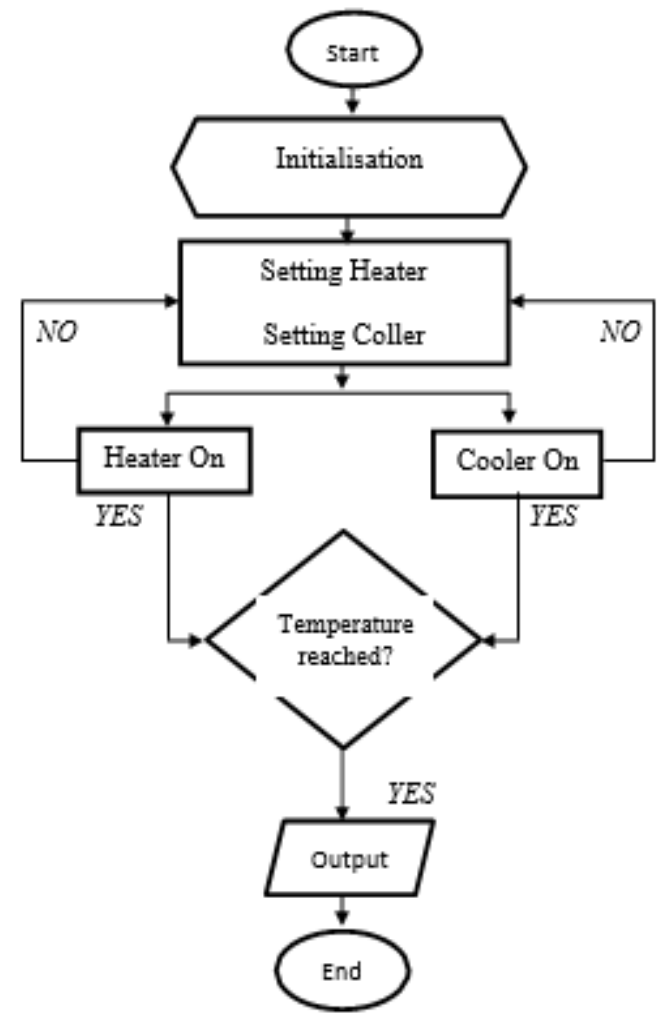

Fig. 2. Systems work flow

A flow chart is a diagram with graphical symbols that expresses the flow of an algorithm or process that displays the steps symbolized in the shape of a box and their sequence by 
connecting each of these steps using the arrows. This diagram can provide step by step for solving the problem that is in the process or algorithm. Device recognition and menu recognition The process of heating and cooling the paraffin. After the temperature is reached the heater, the coller stops operating and the buzzer sounds. As the output or output from the heating and cooling block End, indicating the device has been completed.

\section{Hardware design}

The design of device is the most important part in making device that will be designed is shown in Figure 3. From the figure, it can be seen that design of the system is designed with concepts based on theories and references related to the device to be designed to make it easier to work on and analyze device. This section will explain the system design of the hardware (hardware).

The hardware is designed to control the workings of the embedding system innovation device equipped with heating and cooling systems. As for the hardware needed for the manufacture of device, namely the LCD circuit, amplifier circuit, and the minimum circuit system At Mega 328p.

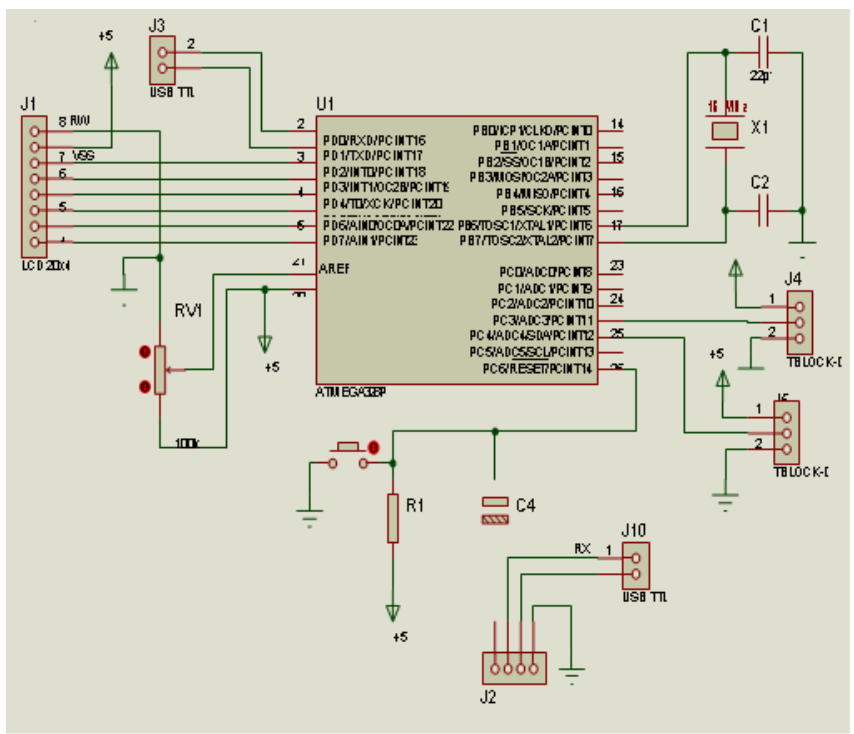

Fig. 3. Minimum system schematic

Arduino uno functions as the brain and controls all activities of the device. This Arduino uno uses ATMega328p which has been equipped with an internal ADC to facilitate the analog converter to digital system. In Arduino Uno there are 6 ADC ports, a port to connect to the LCD character, and there is also a USB to TTL port that functions to enter the program needed by the module.

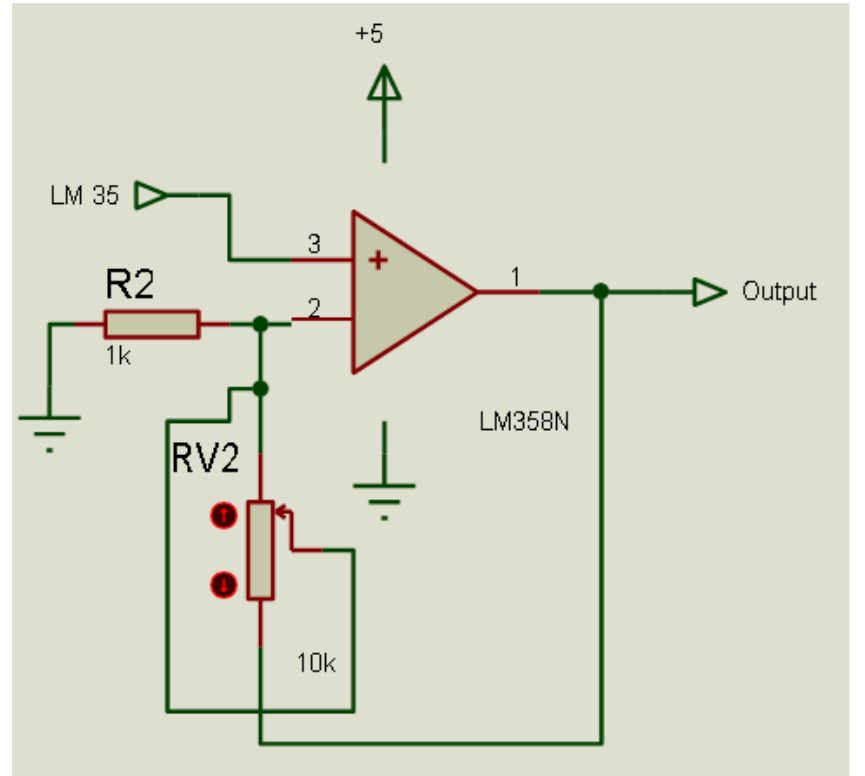

Fig. 4. Amplifier schematic

When the LM35 temperature sensor detects the temperature of the room, the change in the output voltage produced is still small, where the change is only about $0.01 \mathrm{~V}$ per change in temperature. Changes in the value of the LM35 sensor output voltage will be amplified by a non-inverting circuit, with a gain value of 55 times adjusted to the reference voltage requirement on the Arduino Uno of $5.0 \mathrm{~V}$. The amplifier circuit design is shown in Figure 4. From the figure, it can be seen that the LM358N is used as the LM35 amplifier

\section{Firmware design}

The program used in making innovation embedding systems using heating and cooling systems is a program in the Arduino application.

\section{E. Data analyze}

In this study, data analysis is calculated from three parameters, namely the average, the deviation, and the error.

Average is the value or result of the division of the amount of data taken or measured by the number of data retrieval or the number of measurements.

The deviation is the difference from the average value of the desired price with the measured value. While Error is the difference between the mean of each data.

Error or deviation of data from the difference between the mean with each data.

\section{RESULT AND DISCUSSION}

In this section there are steps to use the device, drawing device, measurement data and analysis of the measurement results. Temperature measurement with the help of a thermometer to find out the average, the deviation and the error so that it can be known whether the device is functioning well or not. And using paraffin as a sample. In this device measurements were made at $50{ }^{\circ} \mathrm{C}$ for the heating block and $17^{\circ} \mathrm{C}$ for the cooler is shown in Figure 5 . 


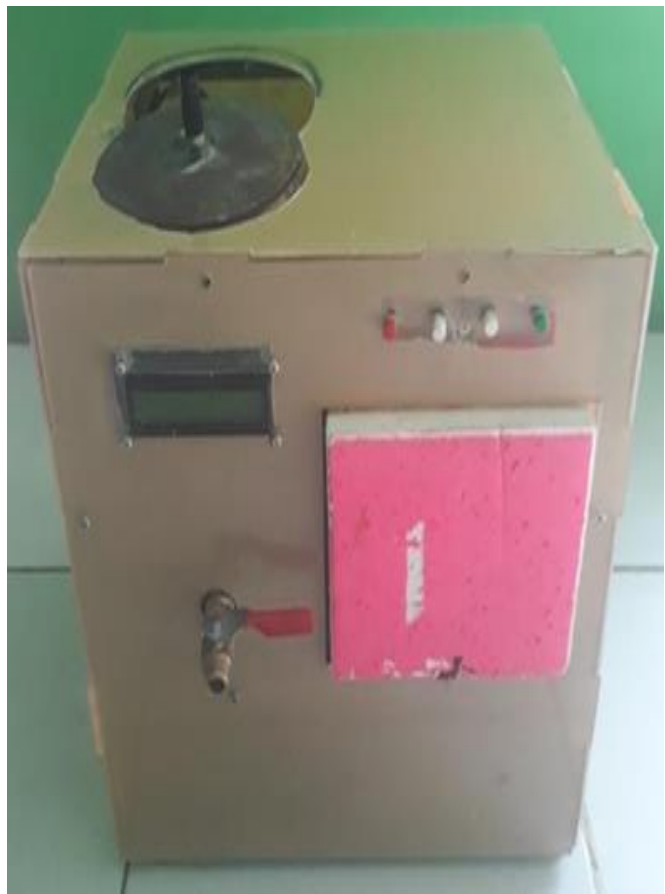

Fig. 5. Device visualisation

\section{A. Measurement result}

After creating the module, the next step is to take measurements. For this reason, the writer collected data through several stages of the measurement process. The purpose of measurement is to find out the level of truth of making device and ensure each component functions according to what is planned.

\section{B. Temperature heater measurement}

Based on the results of data collection, the results obtained from the measurement of the heater temperature, the error value that exceeds the tolerance in section 11 gets a temperature value of $52.13{ }^{\circ} \mathrm{C}$ this value exceeds the temperature tolerance limit at $50{ }^{\circ} \mathrm{C}$ testing and the average value of the comparator is $51.81{ }^{\circ} \mathrm{C}$ while the the average value of the LCD display is $50.93{ }^{\circ} \mathrm{C}$. Then from the results of the measurement value of the equipment displayed in the LCD or comparator get an error of 0.88 and an error percentage of $1.69 \%$.

\section{Temperature cooler measurement}

Based on the results of data retrieval, the results obtained from the measurement of coolant temperature, error values that exceed in sections $8,9,15$, and 17 ie get values below 15 ${ }^{\circ} \mathrm{C}$ this value exceeds the temperature tolerance limit on testing $17{ }^{\circ} \mathrm{C}$ and the average value of comparator namely $17,720 \mathrm{C}$ while the average value of the LCD display is $16,150 \mathrm{C}$. Then from the results of the measurement value of the equipment displayed in the LCD or comparator get an error of 1.57 and an error percentage of $8.86 \%$.

\section{Overall system performance}

To conclude that the module has been functioning properly if the temperature percentage results $50^{\circ} \mathrm{C}$ the error is $\leqslant 5 \%$, while the percentage temperature is $20^{\circ} \mathrm{C}$ down the error is $\leqslant 2 \%$. After testing the module, the author can conclude that the module test results function properly, although the reading results are different from the comparison device, the errors obtained are quite small. This is because there are differences in the working system of device and programs in the module made by the author of the comparison device, where the Thermometer comparison device can produce measurements continuously and the level of accuracy that has been tested. While the temperature reading module has a delay of 5 to 10 seconds to do the temperature reading because the components used are not in accordance with the manufacturer's standards.

\section{CONCLUSION}

This embedding system can be used as desired, from the heating process of the paraffin to liquid to the cooling process of the liquid paraffin network to freezing. The results of heating sample measurements at a temperature of $50{ }^{\circ} \mathrm{C}$ get an average value of the initial sample $15 \mathrm{ml}$, the final sample 9.2 , and obtain a difference of $5.8 \mathrm{ml}$ reduction. While the measurement of the cooling sample at a temperature of $17{ }^{\circ} \mathrm{C}$ gets an average value of the initial sample 9.2, the final sample 8.5 , and gets a difference of $0.7 \mathrm{ml}$. From the results of testing the heating temperature at $50{ }^{\circ} \mathrm{C}$, the percentage of error obtained is $1.69 \%$ this value is still within tolerance because the error is still below 5\%. While the results of testing the cooling temperature at a temperature of $17{ }^{\circ} \mathrm{C}$, the overall error percentage obtained by $8.86 \%$ this value exceeds the reasonable limit of the temperature sensor for measurements of $20^{\circ} \mathrm{C}$ and below that is equal to $2 \%$, but the cooling section has no effect on the sample.

\section{REFERENCES}

[1] Z. Liu, L. Chang, Z. Luo, and F. Ning, "Design of Vehicle-Mounted Medical Temperature Control System," in 2016 Sixth International Conference on Instrumentation \& Measurement, Computer, Communication and Control (IMCCC), 2016, vol. 1, pp. 57-60.

[2] L. Shuai, X. Wang, and S. Li, "Fuzzy PID Controller Design of Air Handling Unit for Constant Temperature and Humidity AirConditioning," in 2016 8th International Conference on Intelligent Human-Machine Systems and Cybernetics (IHMSC), 2016, vol. 02, pp. 410-414.

[3] V. Radu, A. Avram, V. Anghel, and G. Brezeanu, "Autotuned PID for accurate temperature control — A hot approach," in 2016 International Semiconductor Conference (CAS), 2016, vol. 2016-Decem, pp. 209212.

[4] A. Xhafa, P. Tuset-Peiro, and X. Vilaiosana, "Live demonstration: Wireless PID control of a thermal process using an ultra-low cost LWIR camera," in 2017 IEEE SENSORS, 2017, vol. 2017-Decem, pp. $1-1$.

[5] K. Janprom, S. Wangnippanto, and W. Permpoonsinsup, "Embedded control system with PID controller for comfortable room," in 2017 International Electrical Engineering Congress (iEECON), 2017, no. March, pp. 1-4.

[6] Y. Han, Q. Li, H. Yang, and W. Chen, "Design optimal temperature control system based on effective informed adaptive particle swarm optimization for proton exchange membrane fuel cell," in 2016 35th Chinese Control Conference (CCC), 2016, pp. 8562-8566.

[7] R. G. Datar, D. S. More, and S. S. Kamble, "Performance Evaluation of Model-based Controllers for Data-driven Models of Temperature Control System employing Embedded Platform," in 2018 International Conference on Computing, Power and Communication Technologies (GUCON), 2018, pp. 913-918.

[8] J. S. Hernandez, R. Rivas-Perez, and J. J. S. Moriano, "Model Reference Adaptive Temperature Control of a Rotary Cement Kiln," in 2018 IEEE PES Transmission \& Distribution Conference and Exhibition - Latin America (T\&D-LA), 2018, pp. 1-4.

[9] Y. Cao, C. Zhong, and K. Qiu, "Design and Experiment about Temperature Control System of Sealing Machine Based on Fuzzy PID," in 2016 8th International Conference on Intelligent HumanMachine Systems and Cybernetics (IHMSC), 2016, vol. 2, pp. 308311 . 
[10] Y. Qiao et al., “Application of Improved Intelligent PID Algorithm in High Precision Thermostatic Control in Trace Water Analyzer," in 2018 IEEE 17th International Conference on Cognitive Informatics \& Cognitive Computing (ICCI*CC), 2018, pp. 440-447.

[11] W. Jiang, Y. Liu, and J. Han, "The design of the all-coefficient adaptive temperature controller based on characteristic model," in 2017 36th Chinese Control Conference (CCC), 2017, pp. 6547-6551.

[12] L. Jingjie, Y. Dongmei, Z. Ruiyi, and Z. Hui, "A humidity control system based on T\&amp;H-decoupling and PID self-tuning fuzzy algorithm," in 2017 13th IEEE International Conference on Electronic Measurement \& Instruments (ICEMI), 2017, pp. 16-21.

[13] C.-C. Tsai and C.-T. Tsai, "Digital command feedforward and PID temperature control for PET stretch blow molding machines," in 2017 11th Asian Control Conference (ASCC), 2017, vol. 2018-Janua, pp. 1128-1133.

[14] M. Li, J. Wei, and T. Shen, "Temperature and humidity decoupling control for enthalpy difference Laboratory," in 2018 Chinese Automation Congress (CAC), 2018, pp. 1174-1178.

[15] R. DU, Q. Chen, and C. Chen, "A Heuristic Control Method for Heating System," in 2018 IEEE 23rd International Conference on Digital Signal Processing (DSP), 2018, vol. 2018-Novem, pp. 1-4.

[16] C. Deng and Z. Wang, "Self-Learning Fuzzy Algorithm Optimized Temperature Control and Efficiency Monitoring of Heat Exchanger," in 2018 37th Chinese Control Conference (CCC), 2018, vol. 2018-July, no. 3, pp. 3394-3399.

[17] L. Zhengxin and Z. Yue, "Application of Fuzzy Control Based on Time Series Prediction Algorithm in Main Steam Temperature System," in 2018 Chinese Automation Congress (CAC), 2018, pp. 116-121.

[18] K. A. Tapia Pantoja and D. F. Coral, "Temperature Controller for a Nanoparticle Synthesis System," in 2018 IEEE ANDESCON, 2018, vol. 00287, no. 2, pp. 1-3.

[19] Y. Sanjaya, A. Fauzi, D. Edikresnha, M. M. Munir, and Khairurrijal, "Air temperature regulation in a chamber for rotary forcespinning," in
2016 International Seminar on Sensors, Instrumentation, Measurement and Metrology (ISSIMM), 2016, pp. 28-31.

[20] L. Jingyun and L. Ping, "Temperature and humidity control with a model predictive control method in the air-conditioning system," in 2017 International Conference on Advanced Mechatronic Systems (ICAMechS), 2017, vol. 2017-Decem, pp. 408-412.

[21] M. W. Hariyanto, A. H. Hendrawan, and R. Ritzkal, "Monitoring the Environmental Temperature of the Arduino Assistance Engineering Faculty Using Telegram,” J. Robot. Control, vol. 1, no. 3, pp. 96-101, 2020.

[22] L. Yu and G. Dai, "Configuration design method of switched thermal power superheated steam temperature control system," in 2016 Chinese Control and Decision Conference (CCDC), 2016, pp. 22682272.

[23] I. Prasojo, A. Maseleno, O. Tanane, and N. Shahu, "Design of Automatic Watering System Based on Arduino," J. Robot. Control, vol. 1, no. 2, pp. 55-58, 2020.

[24] H. Huang, S. Fu, P. Zhang, and L. Sun, "Design of a Small Temperature Control System Based on TEC," in 2016 9th International Symposium on Computational Intelligence and Design (ISCID), 2016, vol. 1, pp. 193-196.

[25] S. Bhujbal, A. Andhale, A. Deshpande, and S. Pimpalnerkar, "Implementation of control algorithm for furnace temperature control in CFD simulation," in 2016 International Conference on Automatic Control and Dynamic Optimization Techniques (ICACDOT), 2016, pp. 110-113.

[26] B. Doicin, M. Popescu, and C. Patrascioiu, "PID Controller optimal tuning," in 2016 8th International Conference on Electronics, Computers and Artificial Intelligence (ECAI), 2016, pp. 1-4.

[27] G. Rata and M. Rata, "Temperature control solution with PLC," in 2016 International Conference and Exposition on Electrical and Power Engineering (EPE), 2016, no. Epe, pp. 571-575. 